\title{
Kanser Hastalarında Konstipasyon Sıklığı ve Gelişme Riskinin İncelenmesi
}

\author{
Nazlı ÖZTÜRK *, Burcu ÇELIK KOCABIYIK **, Fatma ARIKAN ***, Hasan ŞENOL COŞKUN ****
}

$\ddot{O} \mathbf{z}$

Giriş: Konstipasyon kanser hastalarında sık görülen semptomlardan biri olup, bu semptomun görülmesinde hareket azlığı, yetersiz sıvı alımı, kemoterapi, radyoterapi gibi tedavi yöntemleri ve opioid kullanımı gibi birçok faktör etkili olabilmektedir. Kanser hastalarının konstipasyon gelişme riski açısından yakından izlenmesi bu semptomun erken dönemde tanılanmasına katkı sağlar. Amaç: Bu çalışmanın amacı onkoloji kliniğinde yatan kanser hastalarında konstipasyon sıklığı/gelişme riski ve konstipasyon gelişmesini etkileyen bazı faktörlerin belirlenmesidir. Yöntem: Tanımlayıcı nitelikteki bu çalışma Ekim 2018-Şubat 2019 tarihleri arasında 18 yaşından büyük, kanser tanısı almış 129 hasta ile yürütülmüştür. Veriler 'Birey Tanılama Formu' ve 'Konstipasyon Risk Değerlendirme Ölçeği' kullanılarak toplanmıştır. Verilerin değerlendirilmesi Ki-kare, Mann-Whitney U testi analizi ile yapılmıştır. Bulgular: Hastaların yaş ortalaması $59 \pm 1.12$ yıl, \%34.2 'si kadın, $\% 65.8$ 'i erkek ve konstipasyon görülme sıklığ $1 \% 62$ 'dir. Hastaların konstipe olmasında sürekli opioid tedavisi alma, hastaneye yatış nedeni ve metastaz varlığına göre istatistiksel olarak anlamlı bir farklılık olduğu belirlenmiştir. Sürekli opioid tedavisi alan ve destek tedavi almak amaçlı hastaneye yatan hastalarda konstipasyon oranı daha yüksekti $(\mathrm{p}<.05)$. Konstipe olmayan hastaların ise konstipasyon gelişme riskinin orta düzeyde $(13.1 \pm 4.3)$ olduğu saptanmıştır. Sonuç: Çalışmamızda onkoloji kliniğinde yatan hastaların çoğunluğunun konstipasyon yaşadığı, sürekli opioid tedavisi alma, destek tedavi alma ve metastaz varlığının hastaların konstipasyon yaşamasında etkili olduğu ve konstipe olmayan kanser hastalarının ise orta düzeyde risk altında olduğu belirlenmiştir.

Anahtar Kelimeler: Onkoloji, Konstipasyon, Hemşirelik.

\section{Abstract
Investigation of Constipation Frequency and Development Risk in Cancer Patients}

Background: Constipation is one of the common symptoms in cancer patients, and many factors such as lack of mobility, insufficient fluid intake, chemotherapy, radiotherapy and opioid use can be effective in this symptom. Close monitoring of cancer patients in terms of the risk of developing constipation contributes to the early diagnosis of this symptom. Objectives: The aim of this study is to determine the frequency / risk of development and some factors affecting the development of constipation in cancer patients hospitalized in the oncology clinic. Methods: This descriptive study in October 2018-February 2019, between the age of 18, was conducted with 129 patients who were diagnosed with cancer. The data were collected using 'Individual Identification Form' and 'Constipation Risk Assessment Scale'. The evaluation of the data was done by Chi-square, Mann-Whitney U test. Results: The mean age of the patients is $59 \pm 1.12$ years, $34.2 \%$ are women, $65.8 \%$ are men and frequency of constipation is $62 \%$. It has been determined that there is a statistically significant difference between the patients being construed and continuous opioid treatment, the reason for hospitalization and the presence of metastasis. Constipation rate was higher in patients who were constantly receiving opioid therapy and hospitalized for supportive treatment ( $<<.05)$. It was found that the risk of developing constipation was moderate level $(13.1 \pm 4.3)$ in patients who were not constipated. Conclusion: In our study, it was determined that the majority of patients hospitalized in the oncology clinic experienced constipation, continuous opioid treatment, supportive treatment and the presence of metastasis were effective in patients' constipation and cancer patients who were not constipated were at moderate risk.

Key Words: Oncology, Constipation, Nursing.

Geliş tarihi: 21.08.2019 Kabul tarihi: 02.07.2020

$\mathrm{K}$ onstipasyon kanser hastalarında $(1,2)$ ağrı ve anoreksiyadan sonra en sık görülen semptomlardan birisidir ve hastalığın ilerleyen dönemlerinde kanser hastalarının \%43-58 inin bu semptomla karşılaştığı bildirilmiştir (1). Opioid analjezik kullanan terminal dönem kanser hastalarında ise konstipasyon görülme sıklığı \%60 -\%87 arasındadır (3). Kanser hastalarında konstipasyon nedenleri; birincil, ikincil ve iyatrojenik olmak üzere üç grupta sınıflandırılabilir (1,4). Birincil nedenler; hareket azlığı, düşük lifli diyet, yetersiz sıvı alımı ve utanma vb. gibi nedenleri kapsamaktadır. İkincil nedenler ise; bağırsak obstrüksiyonu, hipokalemi ve hiperkalsemi gibi metabolik etkiler ya da aşırı kusma sonucu fazla sıvı kaybını içermektedir (4). İyatrojenik konstipasyon ise tedavide kullanılan farmakolojik ajanların ve tıbbi müdahalelerin birer sonucudur (1-5). Opioidler, kemoterapik ilaçlar, antiemetikler, cerrahi ve radyoterapi konstipasyona neden olan faktörlerdir ve kanser hastaları en s1k iyatrojenik nedenlere bağlı olarak konstipasyon deneyimlemektedir (1-5). Konstipasyon iyi yönetilmez ise defekasyon sırasında sert dışkılama ve aşırı zorlanma hastada anksiyete ve sıkıntıya, rektal ve abdominal ağrıya neden olur $(4,5)$. Ayrıca organ prolapsusları, hemoroidler, anal fissür, fekal tıkaç, bağırsak tıkanması, bağırsak delinmesi gibi hastaların iyilik halini etkileyen birçok olumsuz duruma yol açmaktadır $(6,7)$.

Kanser tedavi sürecinde, hastanın iyilik halini olumsuz etkileyen anoreksiya, bulantı, abdominal distansiyon, kusma, üriner retansiyon, konfüzyon, fekal inkontinans, konstipasyon gibi semptomlar; tedavi dozunun azaltılmasına, tedavinin sonlandırılmasına ya da hastaların tedaviyi bırakmalarına sebep olmaktadır (6-8). Bu nedenle konstipasyonun tanımlanmasında evet/hayır yanıtının yetersiz olduğu bildirilmektedir. Ayrıca kanser hastalarında opioid kullanımı, fiziksel aktivite yetersizliği, iştahta azalma ve sıvı alımının yetersizliği gibi hastalık sürecinde görülen sorunlar konstipasyon gelişme riskini artırdığı için kapsamlı değerlendirme önerilmektedir $(4,6)$.

Bu çalışma, İkinci Uluslararası Sağlık Bilimleri ve Yaşam Kongresinde Sözel Bildiri olarak sunulmuştur (24-27 Nisan 2019, Burdur, Türkiye) *Arş. Gör., Akdeniz Üniversitesi Hemşirelik Fakültesi, Antalya. E-posta: nazliozturk@akdeniz.edu.tr, ozturknaz@outlook.com, ORCID: 0000-0003-2108-0735 **Uzm. Hem., Akdeniz Üniversitesi Hastanesi, Antalya. E-posta: nesi102005@ hotmail.com, ORCID: 00000003-4166-9408 ***Dr.Öğr.Üyesi, Akdeniz Üniversitesi Hemşirelik Fakültesi, Antalya. E-posta: farikan@akdeniz.edu.tr, ORCID: 00000003-0481-1903 ****Prof. Dr. Akdeniz Üniversitesi Hastanesi Tibbi Onkoloji Bilim Dalı, Antalya. E-posta: hs.coskun@yahoo.com, ORCID: 0000-0003-2969-7561 
Kanser hastalarında konstipasyon semptomunun erken dönemde tanılanmasında Dünya Gastroenteroloji Örgütü’nün önerdiği ROMA III tanı kriterlerinin kullanılması, konstipe olmayan hastalarda ise risk değerlendirmesinin yapılması bu semptomun onkoloji hemşireleri tarafından proaktif dönemde ele alınmasına katkı sağlamaktadır $(8,9,10)$.

Araştırma Sorulart

- Onkoloji kliniğinde yatan kanser hastalarında konstipasyon sıklığı nedir?

- Onkoloji kliniğinde yatan kanser hastalarında konstipasyon görülme durumunu etkileyen faktörler nelerdir?

- Onkoloji kliniğinde yatan konstipe olmayan kanser hastaları konstipasyon açısından ne düzeyde risk altındadır?

Amaç

$\mathrm{Bu}$ çalışmanın amacı onkoloji kliniğinde yatan kanser hastalarında konstipasyon sıklığı, konstipasyon gelişme riski ve konstipasyonu etkileyen faktörlerin belirlenmesidir.

\section{Araştırmanın Tipi}

\section{Yöntem}

Bu çalışma tanımlayıcı ve kesitsel nitelikte bir çalışmadır.

Araştırmanın Yeri ve Zamanı

Bu çalışma Ekim 2018-Şubat 2019 tarihleri arasında Türkiye'nin güneyindeki bir üniversite hastanesinin Tıbbi Onkoloji I ve II Kliniklerinde yürütülmüştür.

\section{Araştırmanın Evreni ve Örneklemi}

Çalışma evrenini bir üniversite hastanesinin tıbbi onkoloji kliniğinde yatan, 18 yaşından büyük, araştırmaya katılmayı kabul eden ve kanser tanısı almış hastalar oluşturmuştur. Hastaların çalışmaya katılmaya gönülsüz olması ve irritabl bağırsak sendromunun bulunması dışlama kriterleri arasındadır. Veri toplama süreci Ekim 2018-Şubat 2019 tarihleri arasında gerçekleştirilmiştir ve 129 hastaya ulaşılmıştır. Örneklem büyüklügünün belirlenmesi için G-Power istatistik analizi yapılmıştır. Örneklem büyüklüğü için hesaplama yapıldığında $\alpha=0.05$ ve 0.80 güç ile Cohen'in etki büyüklüğünün w $=0.5$ için ulaşılması gereken minimum örneklem sayısı 124 kişi olarak belirlenmiştir (11).

\section{Veri Toplama Araçlart}

Birey Tanılama Formu

Birey Tanılama Formu toplanan literatür bilgileri 1şı̆̆ında araştırmacılar tarafindan oluşturulmuştur $(1,2,6)$. Birey Tanılama Formu; sosyodemografik veriler, hastalığa ilişkin veriler olmak üzere iki bölümden oluşmaktadır ve toplam 12 maddelidir. Birey tanılama formunun sonunda kanser hastalarında konstipasyonu değerlendirmeye yönelik olarak Dünya Gastroentereoloji Örgütü (DGÖ)' nün önerdiği 5 maddeli ROMA III tanı kriterleri bulunmaktadır. Buna göre hastanın son 12 haftalık dönemde; haftada $3^{\prime}$ ten az bağırsak hareketlerinin olması, defekasyonlarının \%25' inden fazlasında sert dışkı bulunması, defekasyonlarının $\% 25$ ' inden fazlasında tam boşalamama hissi, defekasyonlarının \%25' inden fazlasında aşırı zorlanma ve defekasyonlarının \%25' inden fazlasında dijital manipülasyon durumları ROMA III tanı kriterleri arasındadır. Hastaların bunlardan en az ikisinin bulunduğunu rapor etmesi durumunda hastada konstipasyon var olarak kabul edilmiştir (12). ROMA III tanı kriterlerini sağlamayan hastalarda konstipasyon yok olarak kabul edilmiş ve Konstipasyon Risk Değerlendirme Ölçeği ile kanser hastasının konstipasyon açısından hangi risk grubunda olduğu değerlendirilmiştir.

Konstipasyon Risk Değerlendirme Ölçeği

Bu ölçek 2004 yılında Richmond J.P. ve Wright M.E. tarafından geliştirilmiştir (13). Koca, Kutlu, Yılmaz, Çeçen ve Esen tarafından 2009 yılında geçerlilik güvenilirlik çalışması yapılmıştır (Cronbach $\alpha=61.9)$ (14). Toplam puan ve alt bölüm korelasyonları $(r=.47-.57)$ anlamlı bulunmuştur. Ölçek; hastane koşulları, yaşam tarzı, fizyolojik ve psikolojik durum, ilaçlar olmak üzere toplam 4 alt boyuttan oluşmaktadır ve her alt boyutta hastaya sorulan soruların cevaplarına yönelik puanlar yer almaktadır. Hastaların ölçekten alacakları minimum puan 0 maksimum puan 63'tür. Ölçeğin sonunda bu puanlar toplanarak hastanın konstipasyon risk grubu tespit edilmektedir. Ölçekten alınan puan $\leq 10$ ise düşük risk grubu, 11-15 arasında ise orta düzey risk grubunda, $\geq 16$ ise kanser hastanın konstipasyon için yüksek risk grubunda olduğunu göstermektedir. Konstipasyon Risk Değerlendirme Ölçeğinden alınan puanlar arttıkça hastada konstipasyon gelişme riski de artmaktadır (14). Ülkemizde konstipasyon gelişme riskinin bu ölçekle değerlendirildiği çalışmalar bulunmakla birlikte, kanser hastalarına uygulandığı bir çalışmaya ulaşılamamıştır.

\section{Verilerin Değerlendirilmesi}

Çalışma verilerinin girilmesi için, lisanslı SPSS (23.0) istatistik paket programı kullanılmıştır. İncelenecek değişkenler için ortalama, medyan ve standart sapmalar hesaplanmıştır. Kanser hastalarında konstipasyon görülme durumuyla yaş, hastaneye yatış nedeni ve sürekli opioid tedavi görme durumu arasında fark olup olmadığını değerlendirmek için Ki-kare, Mann-Whitney U testleri yapılmıştır.

\section{Araştırmanın Etik Yönü}

Çalışma için Klinik Araştırmalar Etik Kurulu' ndan (26.09.2018, Karar No: 675) ve ilgili hastaneden kurum izni alınmış olup, çalışmaya katılmaya gönüllü olan hastalardan bilgilendirilmiş onam formu alınmıştır. Konstipasyon Risk Değerlendirme Ölçeği kullanımı için gerekli izinler alınmıştır. Çalışmaya katılan kanser hastalarına verilerin bu çalışma kapsamında kullanılacağı konusunda bilgi verilmiş olup, araştırma ve yayın etiğine uyulmuştur. 


\section{Bulgular}

Hastaların yaş ortalamasının $59 \pm 1.12$ yıl (medyan = 60 yıl), \%34.2'isinin kadın, \%65.8'inin erkek, \%65.9'unun ilköğretim mezunu olduğu, \%79.1'inin metastazının bulunduğu, \%59.7'sinin sürekli opioid tedavisi aldığı saptanmıştır (Tablo 1). Buna ek olarak hastaların tanı yılı ortalama $2.3 \pm 2.7$ (Medyan = 1.2 yıl) yıldır. Onkoloji kliniğinde yatan hastaların \%39.5'inin daha önceden kemoterapi aldığı belirlendi. Hastaların kliniğe yatış nedeni \%78.3 oranında destek tedavisi (ağrı yönetimi, solunum ve beslenme desteği) alma idi. Hastaların \%80.6'sının oral beslenebildiği, \%14'ünün total parenteral nutrisyon desteği aldı̆̆ belirlenmiştir (Tablo 1).

Tablo 1. Hastaların Sosyodemografik, Hastalık ve Tedaviye İlişkin Bazı Özellikleri (*n=129)

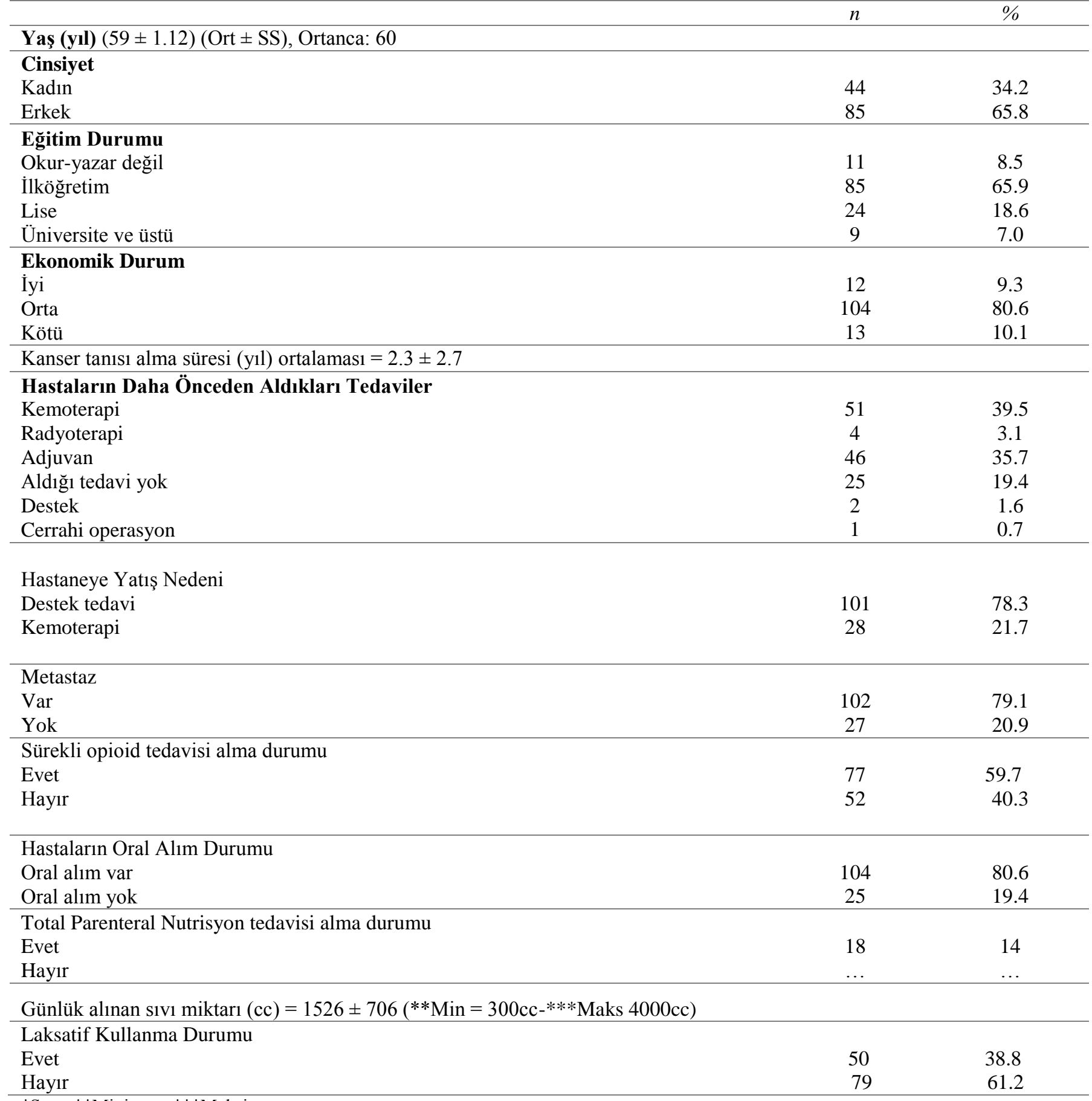

*Say1 **Minimum ***Maksimum

Onkoloji kliniğinde yatan konstipe olan ve olmayan hastaların yaş ortalamaları arasında farklılık bulunmamıştır $(p=$ .87) (Tablo 2). 
Tablo 2. Kanser Hastalarındaki Konstipasyon Durumunun Yaşa Göre Karşılaştırılması Konstipe Olan Hastalar Konstipe Olmayan Hastalar $(n=49)$

\begin{tabular}{|c|c|c|c|c|c|c|c|c|c|}
\hline \multirow{3}{*}{ Yaş } & \multicolumn{4}{|c|}{$\begin{array}{l}\text { Konstipe Olan Hastalar } \\
\qquad(\mathrm{n}=80)\end{array}$} & \multicolumn{4}{|c|}{ Konstipe Ulmayan Hastalar $(n=49)$} & \multirow[b]{2}{*}{$* * * p$} \\
\hline & $n$ & *Ort & $* * S S$ & $\begin{array}{c}\text { Ortanca } \\
\text { (Min- } \\
\text { Maks) }\end{array}$ & $n$ & Ort & $S S$ & $\begin{array}{c}\text { Ortanca } \\
(\text { Min-Maks) }\end{array}$ & \\
\hline & 80 & 59.4 & 11.8 & $\begin{array}{c}60 \\
(36-83)\end{array}$ & 49 & 58.2 & 12.3 & $\begin{array}{c}60 \\
(30-80)\end{array}$ & .873 \\
\hline
\end{tabular}

*Ortalama **Standart Sapma ***Mann Whithney U Testi

Kanser hastalarında cinsiyet ve opioid olmayan ilaç kullanma durumuna göre konstipasyon durumunda fark bulunmaz iken $(p=.086, p=.885)$; metastaz varlığ1, hastaneye yatış nedeni ve sürekli opioid kullanma durumuna göre konstipe olma durumunun istatistiksel olarak anlamlı farklılık gösterdiği belirlendi $(p=.006, p=.006, p=.041)($ Tablo 3$)$.

Tablo 3. Kanser Hastalarındaki Konstipasyon Durumunun Bazı Değişkenlere Göre Karşılaştırılması

\begin{tabular}{|c|c|c|c|}
\hline \multirow[t]{2}{*}{ Özellikler } & $\begin{array}{c}\text { Konstipasyon var } \\
(\mathbf{8 0}, \%)\end{array}$ & $\begin{array}{c}\text { Konstipasyon yok } \\
(49, \%)\end{array}$ & \multirow[t]{2}{*}{$X^{2}$} \\
\hline & $\%$ & $\%$ & \\
\hline
\end{tabular}

\begin{tabular}{|c|c|c|c|c|c|c|}
\hline $\begin{array}{l}\text { Cinsiyet } \\
\text { Kadin } \\
\text { Erkek }\end{array}$ & $\begin{array}{l}32 \\
48\end{array}$ & $\begin{array}{l}40.0 \\
60.0\end{array}$ & $\begin{array}{l}12 \\
37\end{array}$ & $\begin{array}{l}24.4 \\
75.6\end{array}$ & 3.253 & .086 \\
\hline $\begin{array}{l}\text { Metastaz Varlığı } \\
\text { Var } \\
\text { Yok }\end{array}$ & $\begin{array}{l}61 \\
19 \\
\end{array}$ & $\begin{array}{l}76.2 \\
23.8\end{array}$ & $\begin{array}{c}41 \\
8\end{array}$ & $\begin{array}{l}83.6 \\
16.4\end{array}$ & 7.450 & .006 \\
\hline $\begin{array}{l}\text { Hastaneye Yatış Nedeni } \\
\text { Destek tedavi* } \\
\text { Kemoterapi }\end{array}$ & $\begin{array}{l}62 \\
18\end{array}$ & $\begin{array}{l}77.5 \\
22.5\end{array}$ & $\begin{array}{l}28 \\
21\end{array}$ & $\begin{array}{l}57.1 \\
42.9\end{array}$ & 5.970 & .015 \\
\hline $\begin{array}{l}\text { Opioid olmayan analjezik } \\
\text { Evet } \\
\text { Hayır }\end{array}$ & $\begin{array}{l}30 \\
50\end{array}$ & $\begin{array}{l}37.5 \\
62.5\end{array}$ & $\begin{array}{l}19 \\
30\end{array}$ & $\begin{array}{l}38.7 \\
61.3\end{array}$ & .021 & .885 \\
\hline $\begin{array}{l}\text { Sürekli opioid tedavisi } \\
\text { Evet } \\
\text { Hayır }\end{array}$ & $\begin{array}{l}53 \\
27\end{array}$ & $\begin{array}{l}63.7 \\
36.3\end{array}$ & $\begin{array}{l}24 \\
25\end{array}$ & $\begin{array}{l}48.9 \\
51.1\end{array}$ & 4.180 & .041 \\
\hline
\end{tabular}

*Ağrı yönetimi, beslenme desteği, solunum desteği gibi kanser ve tedavisine bağlı semptomların yönetimi için yapılan tedavi

Tablo 4'e göre bu çalıșmaya katılan 129 kanser hastasının \%62'sinde konstipasyon olduğu saptanmıștır (Tablo 4). Kanser hastalarının \%56.6'sında haftada 3'ten az bağırsak hareketleri olduğu, \%52.7'sinin defekasyonlarının \%25'inden fazlasında sert dişkı bulunduğu, \%46.5'inde defekasyonlarının \%25'inden fazlasında tam boşalamama durumu varlı̆̆ saptanmıştır (Tablo 4).

Tablo 4. Kanser Hastalarının Konstipasyon Tanı Kriterleri Bulunma Durumuna Göre Dağılımı

\begin{tabular}{|c|c|c|c|c|}
\hline & \multicolumn{2}{|c|}{ Var } & \multicolumn{2}{|c|}{ Yok } \\
\hline & $n$ & $\%$ & $n$ & $\%$ \\
\hline $\begin{array}{l}\text { 1. Haftada üçten az bağırsak hareketlerinin } \\
\text { var olma durumu }\end{array}$ & 73 & 56.6 & 56 & 43.4 \\
\hline $\begin{array}{l}\text { 2. Defekasyonların } \% 25^{\prime} \text { inden fazlasında } \\
\text { sert dişkı bulunma durumu }\end{array}$ & 68 & 52.7 & 61 & 47.3 \\
\hline $\begin{array}{l}\text { 3. Defekasyonların } \% 25^{\prime} \text { inden fazlasında } \\
\text { tam boşalamama durumu }\end{array}$ & 60 & 46.5 & 69 & 53.5 \\
\hline $\begin{array}{l}\text { 4. Defekasyonların } \% 25 \text { inden fazlasında } \\
\text { aşırı zorlanma durumu }\end{array}$ & 43 & 33.3 & 86 & 66.7 \\
\hline $\begin{array}{l}\text { 5. Defekasyonların } \% 25^{\prime} \text { inden fazlasında } \\
\text { dijital manüplasyon durumu }\end{array}$ & 6 & 4.7 & 123 & 95.3 \\
\hline 6. Hastada konstipasyon bulunma durumu & 80 & 62.0 & 49 & 38.0 \\
\hline
\end{tabular}




\section{Konstipasyon Risk Değerlendirme Ölçeği Bulgulart}

$\mathrm{Bu}$ çalışmada konstipe olmayan kanser hastalarının Konstipasyon Risk Ölçeği cinsiyet, hareketlilik, lif alımı, sıvı alımı ve kişisel inançların yer aldığı 1. alt boyuttan aldıkları puan ortalaması $4.69 \pm 1.9$ 'dur. Hastaların hastane tuvaletlerini kullanırken bağırsak boşaltımı için zorlanma durumları ile sürgü kullanırken zorlanma durumlarını içeren 2. alt boyuttan aldıkları ortalama puan $1.42 \pm 1.0$ olarak saptanmıştır. Hastaların fizyolojik (Metabolik hastalıklar, pelvik durumlar, endokrin hastalıklar vb.) ve psikolojik (psikiyatrik hastalıklar ve öğrenme zorlukları) durumlarını içeren parametrelerin yer aldığ 3 . alt boyut puan ortalamaları $1.30 \pm 2.0$ 'dir. Hastaların Konstipasyon Risk Ölçeği 4. alt boyutu (Konstipasyon riskini artıran ilaçlar) puan ortalaması $5.44 \pm 3.3$ 'dir. Konstipe olmayan 49 hastanın Konstipasyon Risk Değerlendirme Ölçeği toplam puan ortalaması ise $13.10 \pm 4.3$ olarak saptanmıştır (Tablo 5). Tablo 5' de konstipe olmayan kanser hastalarının Konstipasyon Risk Değerlendirme Ölçeği Risk Gruplarına göre dağılımı yer almaktadır. Buna göre hastaların \%51'inin konstipasyon için orta risk grubunda, $\% 26.5$ ' inin düşük risk grubunda ve \%22.4'ünün ise yüksek risk grubunda olduğu belirlenmiştir.

Tablo 5. Konstipe Olmayan Kanser Hastalarının Konstipasyon Risk Dĕgerlendirme Ölçeği ve Alt Boyutlarından Aldıkları Puan Ortalamalart ve Risk Grupları $(n=49)$

Toplam ve Alt Boyutlar

\begin{tabular}{lcc} 
Toplam ve Alt Boyutlar & Min-Maks & $*$ Ort $\pm(S S)$ \\
\hline Alt Boyut 1 & $1-8$ & $4.69 \pm 1.94$ \\
\hline Alt Boyut 2 & $0-4$ & $1.42 \pm 1.08$ \\
\hline Alt Boyut 3 & $0-8$ & $1.30 \pm 2.01$ \\
\hline Alt Boyut 4 & $0-14$ & $5.44 \pm 3.31$ \\
\hline Ölçek Toplam Puanı & $5-23$ & $13.10 \pm 4.35$ \\
\hline Risk Grupları & $\%$ & \\
\hline $\begin{array}{l}\text { Konstipasyon İçin Düşük Risk Grubu } \\
\text { (puan } \leq 10)\end{array}$ & 26.5 & \\
\hline
\end{tabular}

Konstipasyon İçin Orta Risk Grubu 51

$(11<$ puan $<15)$

Konstipasyon İçin Yüksek Risk

Grubu (puan $\geq 16$ )

Toplam 100

*Ortalama ve Standart Sapma

\section{Tartışma}

Konstipasyon kanser hastalarında sık görülen bir sorun olup, ciddi rahatsızlıklara neden olabilen ve hastalar için stres kaynağı olan bir durumdur $(3,14)$. Bu çalışmada hastaların \%62'sinde konstipasyon saptanmıştır. Literatürde kanser hastalarının \%43$\% 58$ ' inde konstipasyon görüldüğü bildirilmiştir (1). Bu çalışma sonuçları literatürle benzerlik göstermekte olup kanser hastalarında konstipasyon oranı yüksek bulunmuştur.

Kanser hastalarında opioid ile ilişkili konstipasyon sıklığı \%40 ile \%80 arasında değişmektedir $(15,16)$. Veiga ve arkadaşları (17) çalışmalarında kanser hastalarının $(n=694) \% 25.8$ 'inde opioid ile ilişkili konstipasyon olduğunu belirtmişlerdir. İleri evre kanser hastalarında besin ve sıvı alımında bozulma, aktivitede sınırlılık (13) ve konstipasyon riskini artıran (antiemetik, sürekli opioid tedavisi ve kemoterapi vb.) ilaçların kullanımı fazladır (5). Konstipasyonun ileri evre kanser hastalarındaki prevelansı ise opioid kullanımındaki artış ve hastaların performans durumunda bozulma sonucu (\%40-90) oldukça yüksektir $(18,19)$. Boland ve Elaine (2017)'nin kanser hastalarında opioidle ilişkili konstipasyon sıklığını değerlendirdikleri çalışmasında ileri evre kanser hastalarında konstipasyon görülme sıklığ $1 \% 52$, opioid tedavi gören ileri evre kanser hastalarında ise \%87 olarak belirtilmiştir (20). Abramowitz ve arkadaşlarının (2013), 520 kanserli hastada opioidle ilişkili konstipasyon ve bağırsak disfonksiyonunu değerlendirdikleri çalışmasında kanser hastalarının \%61.7'sinin opioidle ilişkili konstipasyon deneyimlediği, laksatif kullanan hastaların \%84.7'sinin ise laksatif kullanımına rağmen konstipasyonunun devam ettiği belirtilmiştir (21). Bu çalışmada hastaların \%59.7'sinin sürekli opioid tedavisi alması, \%69.3'ünün kanser ve tedavisine bağlı gelişen semptomlar sonucu destek tedavisi için hastaneye yatması konstipasyon oranının yüksek olmasında etkilidir. Opioidler, bağırsaktaki düz kasların reseptörleri ile birleşip kasların kasılmasını azaltarak peristaltizmin azalmasına neden olur. Buna bağlı olarak kolonik geçiş süresi uzar, bu da giderek artan sıvı ve elektrolit emilimine neden olarak feçesin daha kuru olmasına dolayısıyla defekasyon sırasında tam boşalamamaya ve defekasyonlarda sert dışkı bulunmasına yol açar $(17,18,22-24)$. Opioid kullanmaya başlayan hastalarda peristaltizm yaklaşık olarak 5-25 dakika sonra etkilenmeye başlar bu yüzden hastalar konstipasyonu uzun süreli opioid kullanımının bir yan etkisi olarak deneyimlemektedir $(16,17)$.

$\mathrm{Bu}$ çalışmada kanser hastalarının yaş, cinsiyet ve opioid olmayan analjezik kullanımının konstipasyon görülme sıklığını etkilemediği belirlenmiştir. Yaş ve cinsiyet faktörlerinin konstipasyon oranları üzerinde istatistiksel olarak anlamlı farklılık yaratmamasıyla birlikte konstipasyon görülme sıklığı kadın hastalarda daha fazlayken, konstipasyon yaşayan hastaların yaş ortalaması da daha yüksektir.

Şendir ve arkadaşlarının (10) ortopedi hastalarında ameliyat sonrası konstipasyon riskini değerlendirdiği bir çalışmada hastaların Konstipasyon Risk Değerlendirme Ölçeği toplam puan ortalaması $12.7 \pm 4.7$ ve Çelik ve arkadaşlarının (25) abdominal cerrahi operasyon sonrası konstipasyon riskini değerlendirdiği bir çalışmada ise $11.7 \pm 7.8$ olarak belirlenmiştir 
(10,25). Bu çalışmada kanser hastalarının konstipasyon açısından orta düzeyde risk (13.10 \pm 4.3$)$ altında olduğu belirlenmiştir. Bunun nedeninin kanser hastalarının alt boyut 1(hareketlilik, lif ve sıvı alımı vb.) ve alt boyut 5(konstipasyon riskini artıran ilaç kullanımı)'teki puan ortalamalarının daha yüksek olmasından kaynaklanmaktadır. Lavan ve arkadaşlarının (2019), onkoloji hastalarında ilaç tedavilerinin yan etkilerini araştırdıkları çalışmasında 350 kanser hastasının \%20'sinde bulantı ve kusma, \%20'sinde ise konstipasyon görüldüğü belirlenmiştir. (26). Aynı çalışmada kanser hastalarının en çok yan etki yaşamasına neden olan ilaçlar arasında \%53.3 (sistemik antikanser tedavileri), \%17.3 (opioidler) yer almaktadır (26). Dzierżanowski ve Ciałkowska-Rysz'ın (2015) palyatif bakım alan hastalarda konstipasyon için davranışsal risk faktörlerini değerlendirdikleri çalışmasında yetersiz sıvı ve besin alımının bağırsak hareketi sıklıklarını azalttığı ve konstipasyon gelişme riskini arttırdığı belirlenmiştir (27).

Konstipasyon kanser hastası için zamanında tanımlanması ve yol açtığı yan etkilerin önlenmesi/en aza indirilmesi gereken önemli bir sorun olmakla birlikte konstipasyonun tanımlanmasında evet/hayır yanıtının yetersiz olduğu bildirilmiştir $(28,29)$. Bu çalışmada konstipasyon değerlendirilmesinde önerilen yöntemlerden biri olan ROMA III tanı kriterleri kullanılmış ve konstipe olmayan kanser hastalarında ise risk değerlendirmesi konstipasyon risk değerlendirme ölçeği ile değerlendirilmiştir. Buna göre onkoloji kliniğinde yatan kanser hastalarında konstipasyon oranlarının yüksek, konstipasyon gelişme riskinin ise orta düzeyde olduğu belirlenmiştir. Konstipasyon semptomunun erken tanılamasında hastalarda son defekasyon tarihi, defekasyon sırasında zorlanma, sert dışkılama, dijital manüplasyon yapma gibi durumların sorgulanması gereklidir (12).

\section{Kisitlılıklar}

Araştırmada örneklem grubunun farklı tıbbi tanılara sahip kanser hastalarından oluşan heterojen bir dağılıma sahip olması ve verilerin tek seferde toplanması konstipasyonu etkileyen faktörlerin izlem sürecinde değerlendirilememesi araştırmanın sınırlı yönlerini oluşturmaktadır.

\section{Sonuçların Uygulamada Kullanımı}

Bu çalışmada konstipasyon semptomu ROMA III tanı kriterlerine göre değerlendirilerek semptomun objektif parametrelerle ölçümünün sağlanmasının önemine dikkat çekilmiştir ve literatüre bu konuda veri sağlanmıştır. Buna ek olarak kanser hastalarının kanser ve semptomları için destek tedavi amacıyla yatışı yapılan, metastazı olan ve opioid kullanan hastalarda konstipasyon/gelişme riskinin daha yüksek olduğu belirlenmiştir. Bu sonuçlar onkoloji hemşirelerinin konstipasyonu/gelişme riskini erken dönemde tanılamanın ve girişimler planlamanın önemini ortaya koymaktadır. Bu sonuçlar doğrultusunda;

- Onkoloji kliniğinde yatan hastalarda konstipasyon değerlendirmesinin evet/hayır şeklinde sorulması yerine ROMA III tanı kriterlerine göre hastaların değerlendirilmesi,

- Hastanın besin ve sıvı alımının diyetisyenle işbirliği içinde çalışılarak desteklenmesi, immobil hastalara yatak içi egzersiz yaptırılması,

- Kanser hastasında ağrı yönetimi iyi yapılarak opioid ile ilişkili konstipasyonun yakından izlenmesi ve konuyla ilgili daha fazla sayıda çalışma yapılması önerilmektedir.

\section{Bilgilendirme}

Araştırma tasarımı ve fikir aşamasında NÖ, FA ve HŞC, verilerin toplanmasında BÇK ve NÖ, verilerin değerlendirilmesi ve raporlanmasında NÖ, FA'nın katkıları bulunmaktadır. Çalışma için Klinik Araştırmalar Etik Kurulu' ndan (26.09.2018, Karar No: 675) ve ilgili hastaneden kurum izni alınmış olup, çalışmaya katılmaya gönüllü olan hastalardan bilgilendirilmiş onam formu alınmıştır. Bu çalışma herhangi bir fon tarafından desteklenmemiştir. Yazarlar arasında herhangi bir çıkar çatışması bulunmamaktadır. Yazarlar çalışmanın yürütülmesinde destek olan kanser hastalarına teşekkür etmektedir.

\section{Kaynaklar}

1. Wickham RJ. Managing constipation in adults with cancer. J Adv Pract Oncol 2017;8(2):149-61.

2. Gonzales LK, Delmastro MA, Boyd DM, Sterling ML, Aube PA, Le RN, et al. Adjusting bowel regimens when prescribing opioids in women receiving palliative care in the acute care setting. Am J Hosp Palliat Care 2016;33(7):6638.

3. McIlfatrick S, Muldrew DHL, Beck E, Carduff E, Clarke M, Finucane A, et al. Examining constipation assessment and management of patients with advanced cancer receiving specialist palliative care: a multi-site retrospective case note review of clinical practice. BMC Palliat Care 2019;18(1):57.

4. Sayın Kasar K, Yıldırım Y. Konstipasyon. İçinde: Yıldırım Y, Fadıloğlu Ç, Palyatif Bakım Semptom Yönetimi ve Yaşam Sonu Bakım. Ankara: Nobel Tip Kitabevleri; 2017: 533-548.

5. Lam WC, Zhong L, Liu Y, Shi N, Ng B, Ziea E et al. Hong Kong Chinese medicine clinical practice guideline for cancer palliative care: pain, constipation, and insomnia. Evid Based Complement Alternat Med 2019; 1-14.

6. Zhe $\mathrm{H}$. The assesment and management of constipation among patients with advanced cancer in a palliative care ward in china: a best practice implementation project. JBI Database of System Rev Implement Rep 2016;14(5):295-309.

7. Bengi G, Yalçın M, Akpınar H. Kronik konstipasyona güncel yaklaşım. Güncel Gastroenteroloji 2014;18(1):72-88.

8. Uysal N, Şenel G, Karaca Ş, Kadıŏ̆ulları N, Koçak N, Oğuz G. Palyatif bakım kliniğinde yatan hastalarda görülen semptomlar ve palyatif bakımın semptom kontrolüne etkisi. Klinik çalışma. Ağrı Dergisi 2015; 27(2):104-10.

9. Karadakovan A. Yaşlı Sağlı̆̆ı ve Bakım. Ankara: Akademisyen Tıp Kitabevi; 2014: 279-95. 
10. Sendir M, Büyükyilmaz F, Asti T, Gürpınar S. Postoperative constipation risk assessment in Turkish orthopedic patients. Gastroenterol Nurs 2012; 35(2):106-13.

11. Cochran WG. Sampling techniques. New York: John Wiley \& Sons; 1977: 1-448. ISBN: 978-0-471-16240-7.

12. Lindberg G, Hamid SS, Malfertheiner P, Thomsen OO, Fernandez LB, Garisch J et al. World Gastroenterology Organisation global guideline: constipation — a global perspective. J Clin Gastroenterol 2011;45(6):483-487.

13. Richmond JP, Wright ME. Review of the literature on constipation to enable development of a constipation risk assessment scale. Clin Eff Nurs 2004;9(1-2):37-48.

14. Kutlu Koca A, Yılmaz E, Çeçen D, Eser E. The reliability and validity of the turkish version of the constipation risk assessment scale. Gastroenterol Nurs 2010;34(3):200-8.

15. Hagmann C, Cramer A, Kestenbaum A, Durazo C, Downey A, Russel M et al. Evidence-based palliative care approaches to non-pain physical symptom management in cancer patients. Semin Oncol Nurs 2018;34(3):227-40.

16. Arthur J, Hui D. Safe opioid use: management of opioid-related adverse effects and aberrant behaviors. Hematol Oncol Clin North Am 2018;32(3):387-403.

17. Veiga DR, Mendonça L, Sampaio R, Lopes JC, Azevedo LF. Incidence and health related quality of life of opioidinduced constipation in chronic noncancer pain patients: a prospective multicentre cohort study. Pain ResTreat 2018; 2018:5704627.

18. Larkin PJ, Cherny NI, La Carpia D, Guglielmo M, Ostgathe C, Scotte F et al. ESMO Guidelines Committee. Diagnosis, assessment and management of constipation in advanced cancer: ESMO Clinical Practice Guidelines. Ann Oncol 2018; 29(4):111-25.

19. Dzierżanowski T, Ciałkowska-Rysz A. The occurrence and risk factors of constipation in inpatient palliative care unit patients vs. nursing home residents. Prz Gastroenterol 2018; 13(4): 299-304.

20. Boland JW, Elaine G. Pharmacological therapies for opioid induced constipation in adults with cancer. Bmj 2017; 358 : j3313.

21. Abramowitz L, Beziaud N, Labreze L, Giardina V, Causse C, Chuberre B et al. Prevalence and impact of constipation and bowel dysfunction induced by strong opioids: a cross-sectional survey of 520 patients with cancer pain: Dyonisos study. J Med Econ 2013; 16.12: 1423-1433.

22. Younes WO, Tawalbeh LI. Bowel management: constipation among patients with cancer. J Palliat Care Med 2017 ;(7)4.

23. Locasale RJ, Datto CJ, Margolis MK, Tack J, Coyne KS. The impact of opioid- induced constipation among chronic pain patients with sufficient laxative use. Int J Clin Pract 2015; 69.12: 1448-1456.

24. Wang PM, Hsu CW, Liu CT, Lai TY, Tzeng FL, Huang CF. Effect of acupressure on constipation in patients with advanced cancer. Support Care Cancer 2019; 1-6.

25. Celik S, Atar NY, Ozturk N, Mendes G, Kuytak F, Bakar E et al. Constipation risk in patients undergoing abdominal surgery. Iran Red Crescent Med J 2015;17(6).

26. Lavan AH, O'Mahony D, Buckley M, O'Mahony D, Gallagher P. Adverse drug reactions in an oncological population: prevalence, predictability, and preventability. Oncologist 2019; 24(9): e968.

27. Dzierżanowski T, Ciałkowska-Rysz A. Behavioral risk factors of constipation in palliative care patients. Supportive Care Cancer 2015; 1787-1793.

28. Wickham RJ. Assessment of constipation in patients with cancer. J Adv Pract Oncol 2016;7(4):457-62.

29. İlaslan E, Özer Z, Kol E. Kolorektal kanserlerde palyatif bakım hemşireliği. JAREN/ Hemşirelik Akademik Araştırma Dergisi 2017;3(1):43-8. 